\title{
Advancement of Powder Spheroidization Process Using a Small Power DC-RF Hybrid Plasma Flow System by Sinusoidal Gas Injection*
}

\author{
Juyong JANG**, Hidemasa TAKANA***, Oleg P. SOLONENKO**** \\ and Hideya NISHIYAMA*** \\ ** Graduate School of Engineering, Tohoku University, \\ 2-1-1 Katahira, Aoba-ku, Sendai, Japan \\ E-mail: jang@paris.ifs.tohoku.ac.jp \\ *** Institute of Fluid Science, Tohoku University, \\ 2-1-1 Katahira, Aoba-ku, Sendai, Japan \\ ${ }^{* * * *}$ Khristianovich Institute of Theoretical and Applied Mechanics,
}

SB RAS, Novosibirsk, Russia

\begin{abstract}
The effect of sinusoidal central gas injection on the in-flight alumina spheroidization process was experimentally clarified by using DC-RF hybrid plasma flow system under constant low input power. Spheroidization ratio was evaluated with correlating to frequency and amplitude of sinusoidal central gas injection, DC arc voltage, and particle size distribution. Spheroidization ratio improves through active mixing of DC-RF hybrid plasma flow with powder by injection of sinusoidal central gas for DC plasma jet forming. The maximum spheroidization ratio of $99 \%$ for processed powder collected at $z=120 \mathrm{~mm}$ was obtained by giving the sinusoidal central gas injection at $f_{c}=2 \mathrm{~Hz}$ with amplitude of $\pm 20 \%$.
\end{abstract}

Key words: DC-RF Hybrid Plasma Flow, Active Mixing Effect of Plasma, Alumina Powder in-Flight Process, Spheroidization Ratio

\section{Introduction}

Spherical powders provide more homogenous and stable particle transportation by enhancing the powder fluidity. This allows fine control of powder feeding rate without clogging problems. Especially, spherical powders are preferred in plasma thermal spray processes for dense coating formation and thin film fabrications ${ }^{(1),(2)}$. Therefore, powder spheroidization processes are essential for high spray processing performance.

In the ceramic powder spheroidization process using thermal plasmas, direct current (DC) plasma jet or radio frequency inductively coupled plasma (RF-ICP) flow is typically utilized for in-flight particle processes ${ }^{(3),(4)}$. DC plasma jet has advantages, such as easy ignition, flow stability, and large momentum for transportation. However, DC plasma jet has disadvantages for particle processing, such as small reaction region, high velocity which leads to less residence time, and so on. On the other hand, RF-ICP flow also has advantages, such as large plasma volume and long residence time of in-flight particles. RF-ICP flow, however, has disadvantages such as flow instability by strong back flow induced by Lorentz force in an RF coil region ${ }^{(5)}$. Therefore, a DC-RF hybrid plasma flow system, which is the RF-ICP flow assisted by the low power DC plasma jet, is expected to overcome such individual disadvantages of the conventional plasma flow generation systems. 
Previous experimental studies have been conducted to obtain the optimum operating flow conditions with pure argon gas for in-flight powder processing for particle size and morphology controls using a DC-RF hybrid plasma flow system at constant low input power based on consideration of correlating plasma flow characteristics ${ }^{(6)-(8)}$. However, the process efficiency such as the number percentage of spheroidized alumina powder remained low due to the low input power. Then, in order to enhance the plasma enthalpy even at constant low input power of $7.7 \mathrm{~kW}$, the experimental study was carried out with Ar-He mixture gas for in-flight alumina powder processing in a DC-RF hybrid plasma flow system. The plasma enthalpy was successfully controlled by mixing a small amount of helium into argon central gas. As a result, powder spheroidization ratio improved by $95 \%$ with $4 \%$ of helium mixture in central gas ${ }^{(9)}$.

It is obvious that the powder spheroidization ratio could be improved by enhancing the heat transfer between particles and plasma flow even at a constant low input power ${ }^{(8),(9)}$. Introducing forced mixing between particles and plasma flow is considered to be one of the most effective methods for the heat transfer enhancement. It would be industrially attractive if the spheroidization ratio improves just by introducing forced mixing without any gas mixture such as helium. Therefore, in this study, sinusoidal central gas is injected to introduce active mixing of DC-RF hybrid plasma flow with powder injection even under constant low input power. The effect of active mixing of plasma flow on the spheroidization process by sinusoidal central gas injection was experimentally clarified. The final objective is to improve the efficiency of the alumina powder spheroidization process through enhancing heat transfer by active mixing of plasma flow with particles by sinusoidal central gas injection.

\section{Experimental setup and operating conditions}

Figure 1 shows a schematic illustration of a DC-RF hybrid plasma flow system. The origin point is located at the exit of the DC plasma torch on the central axis. The detailed

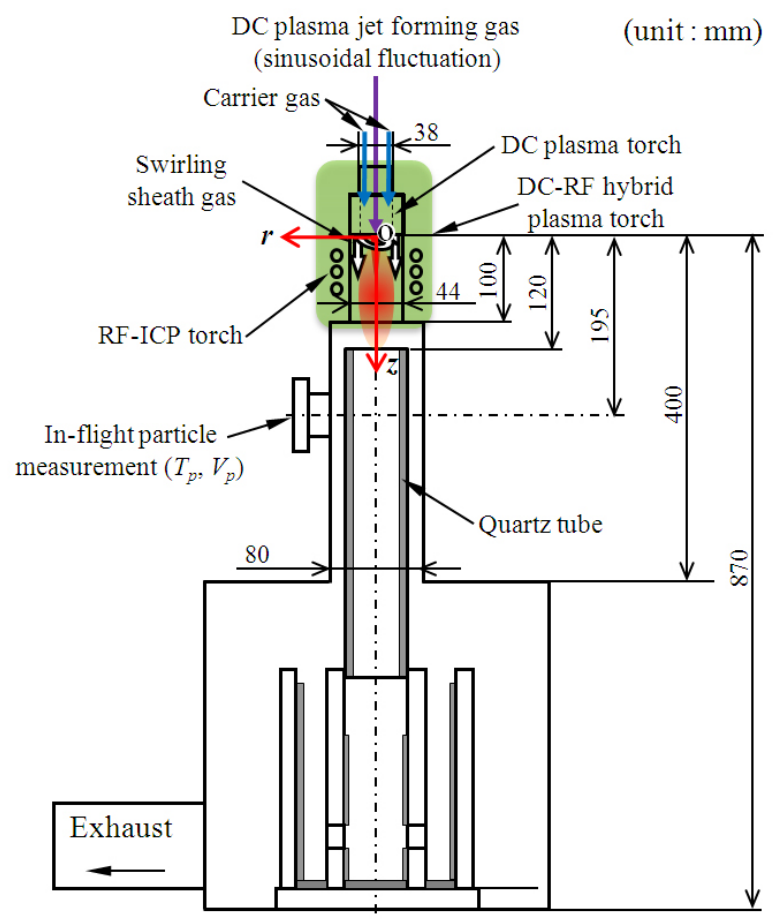

Fig. 1 Schematic illustration of a DC-RF hybrid plasma flow system for in-flight powder process ${ }^{(8),(9)}$ 


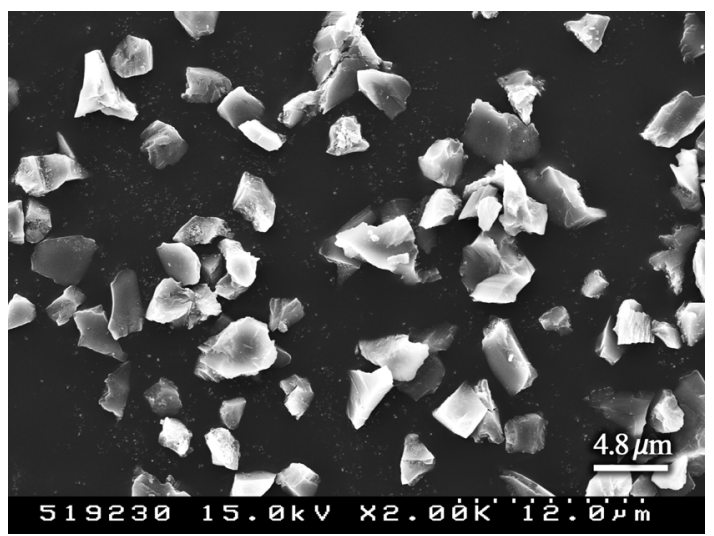

Fig. 2 SEM micrograph of alumina precursor

schematic illustration of the DC-RF hybrid plasma torch is described in Ref. (9). The main working gas is argon. The operating pressure is $20 \mathrm{kPa}$. The DC power of $1.2 \mathrm{~kW}$ and RF power of $6.6 \mathrm{~kW}(4 \mathrm{MHz})$ are supplied in this system. Rough estimations of heat losses to cooling water are $1.47 \mathrm{~kW}$ in the DC-RF hybrid plasma torch and $0.79 \mathrm{~kW}$ in the collecting chamber without powder injection, respectively. The flow rates of swirling sheath gas and central gas are 20 and $5 \mathrm{~N} \ell / \mathrm{min}$, respectively. The total central gas flow rate consists of DC plasma jet forming gas of $4.2 \mathrm{~N} \ell / \mathrm{min}$ and particle carrier gas of $0.8 \mathrm{~N} \ell / \mathrm{min}$. Irregular shaped alumina $\left(\mathrm{Al}_{2} \mathrm{O}_{3}\right)$ powder with averaged size of $3.8 \mu \mathrm{m}$ as shown in Fig. 2 is supplied directly into the DC torch nozzle at $0.85 \mathrm{~g} / \mathrm{min}$ in average for limited constant low input power. The detail description of particle injection point is found in Ref. (9). The melting temperature of alumina is $2319 \mathrm{~K}$.

A silicon photodetector (S2383, HAMAMATSU Inc.) with sensitive wavelength of 780 to $820 \mathrm{~nm}$ detects light emission intensity from plasma flow. Four photodiode sensors are axially installed beside the DC-RF hybrid torch at $r=135 \mathrm{~mm}$ and $z=5,25,40$, and 65 $\mathrm{mm}$, which observe fluctuating plasma emission in the viewing angle of 16 degrees. Plasma emission is measured by the photodiode 1-2 (PD 1-2) in the upstream of RF coil and the photodiode 3-4 (PD 3-4) in the downstream of RF coil. The photodiode array provides clear understanding of the plasma thermofluid flow behavior depending on central gas conditions. The sinusoidal fluctuation is only given to the DC plasma jet forming gas under the constant particle carrier gas. The frequency $\left(f_{c}\right)$ and amplitude of the sinusoidal fluctuation are controlled by a mass flow controller (MFC; SEC-E50, Horiba Inc.). Because of relatively long response time of the MFC, the flow frequency and amplitude of sinusoidal gas flow rate are limited to 1-3 Hz with amplitude of 1-2 N $\ell / \mathrm{min}$. In-flight alumina particle velocity is measured by the particle trajectory velocimetry (PTV) method. In-flight alumina particles temperature is measured by the two-wavelength pyrometry at 700 and $800 \mathrm{~nm}$ during in-flight powder processing ${ }^{(8)}$. Because these wavelengths in argon plasma are undetectable, the thermal emission from particles is distinguished clearly from the direct plasma emission. Processed powder attached on the quartz tube is collected at $z=120 \mathrm{~mm}$. The alumina particle size distribution with a particle size analyzer (MT3000, Microtrac Inc.) is carried out after ultrasonic treatment for $90 \mathrm{sec}$. The morphology and size of alumina are observed by a scanning electron microscopy (SEM; SU6600, Hitachi Inc.). From the SEM micrographs, spheroidization ratio is evaluated as the number percentage of spherical particles to the total number of particles.

\section{Experimental results and discussion}

Figures 3 (a) and (b) show time evolution of DC arc voltage and current, and emission intensity in the RF coil region with constant central gas injection and sinusoidal central gas 


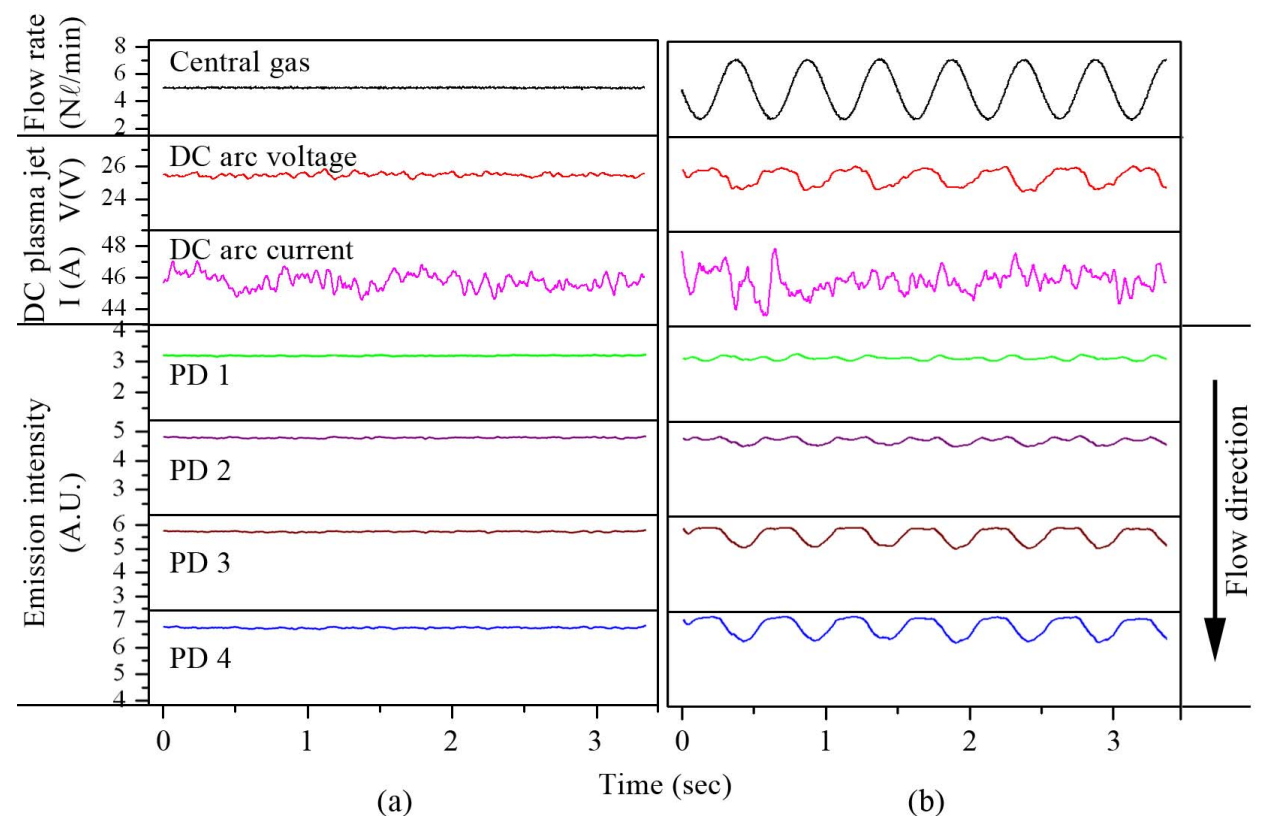

Fig. 3 Time evolution of DC arc voltage and current, and emission intensity in the RF coil region with (a) constant central gas injection and (b) sinusoidal central gas injection at $f_{c}=$ $2 \mathrm{~Hz}$ with amplitude of $\pm 40 \%$

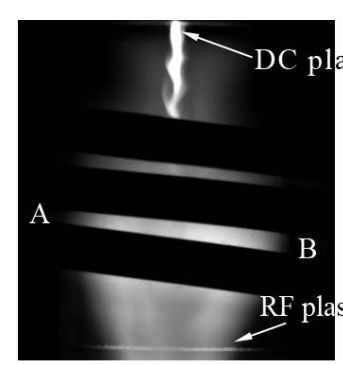

(a)

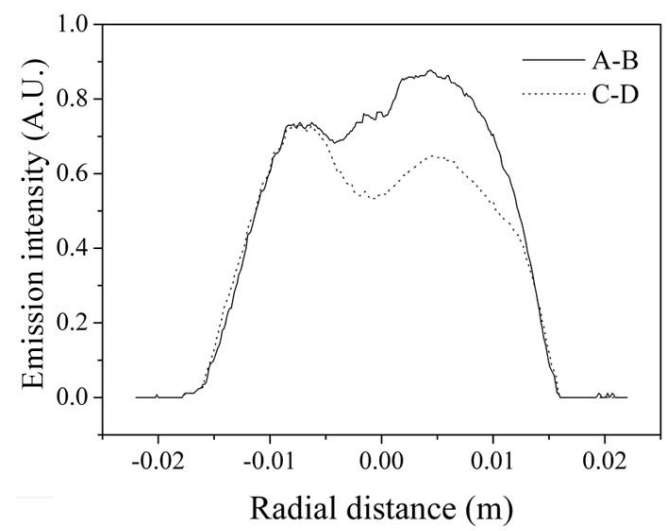

(c)

Fig. 4 Snapshots of DC-RF hybrid plasma flow at (a) 23.5 and (b) $21.8 \mathrm{~V}$ of DC arc voltage, and (c) emission distribution along A-B and C-D injection at $f_{c}=2 \mathrm{~Hz}$ with amplitude of \pm $40 \%$ without particle injection. For clear understanding of the effect of sinusoidal central gas injection, the result with relatively large amplitude of $\pm 40 \%$ is shown. DC arc voltage with sinusoidally fluctuating central gas is measured. The DC arc voltage is recorded at the sampling frequency of $1 \mathrm{kHz}$ by applying median filter. The DC arc voltage and emission intensity of the plasma flow fluctuate at the same frequency with that of the sinusoidal central gas as shown in Fig. 3 (b). In the DC torch, the arc root is formed perpendicular to the gas flow and changes the arc length because of the sinusoidal central gas. The sinusoidal central gas injection surely affects the DC arc voltage as shown in Fig. 3 (b). The periodical DC arc voltage fluctuation indicates the variation of electrical resistance of DC plasma jet caused by arc root fluctuation (10), (11). This arc root fluctuation comes from the unbalance between Lorentz force and drag force induced by sinusoidal central gas injection. The averaged DC input power is nearly the same regardless of 


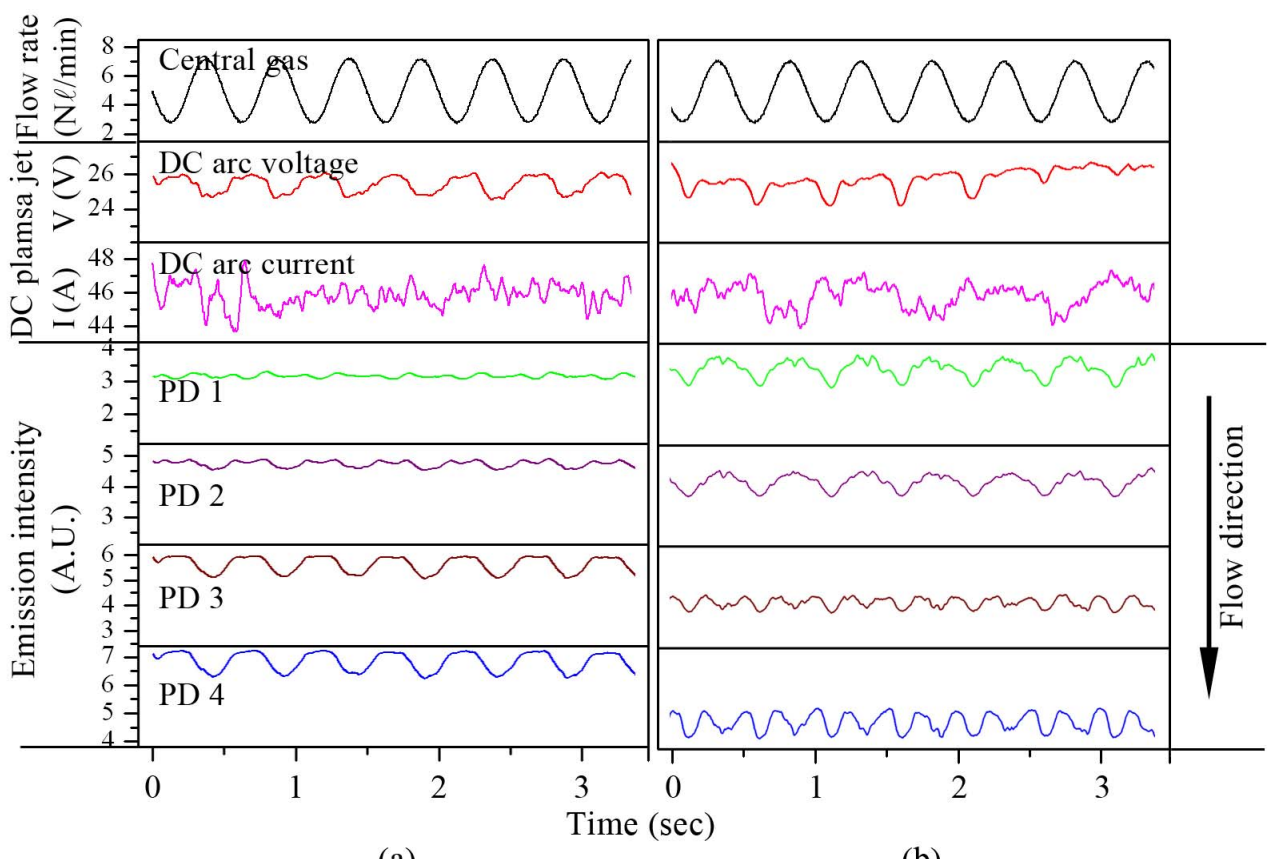

(a)

(b)

Fig. 5 Time evolution of DC arc voltage and current, and emission intensity in the RF coil region (a) without and (b) with particle injection under sinusoidal central gas injection at $f_{c}$ $=2 \mathrm{~Hz}$ with amplitude of $\pm 40 \%$

the sinusoidal central gas. DC arc voltage tends to respond to the flow rate of sinusoidal central gas with delay of $0.4 \mathrm{sec}$. The sinusoidal central gas flow rate obviously influences DC arc voltage and also emission from the plasma flow. The emission intensity from the plasma flow gradually increases to the axial direction in the DC-RF hybrid torch in both cases with or without periodic fluctuation of central gas.

Figures 4 (a) and (b) show snapshots of DC-RF hybrid plasma flow at high and low DC arc voltages. The photographs are taken by a high speed camera (FASTCAM-SA5, Photron Inc.) with exposure time of 369 ns. DC plasma jet elongates and becomes unstable at the high DC arc voltage as shown in Fig. 4 (a). On the other hand, DC plasma jet shrinks and relatively becomes stable at the low DC arc voltage as shown in Fig. 4 (b). The distribution of emission intensity from the RF plasma flow along A-B and C-D is shown in Fig. 4 (c). The plasma emission in the RF coil region is stronger in the case of the high DC arc voltage. The plasma emission intensity becomes higher near the central axis due to the elongation of DC plasma jet. The fluctuating length of DC plasma jet appears periodically with the sinusoidal DC arc voltage caused by sinusoidal central gas injection.

Figures 5 (a) and (b) show time evolution of DC arc voltage and current, and emission intensity in the RF coil region without and with particle injection under sinusoidal central gas injection at $f_{c}=2 \mathrm{~Hz}$ with amplitude of $\pm 40 \%$. By comparing Fig. 5 (b) with Fig. 5 (a), the emission intensity of the plasma flow decreases more along the flow direction with particle injection and the frequency of the emission intensity increases in the downstream of the RF coil. The decrease in the emission intensity corresponds to decrease in plasma temperature due to heat transfer between plasma flow and in-flight particles by active mixing. The significant decrease in the emission intensity is observed especially in the downstream of the RF coil. This indicates that melting and partial evaporation of the powder occur actively in the downstream of the RF coil. The increase in the emission frequency in the downstream of the RF coil may come from the pulsating particle injection caused by the sinusoidal central gas injection. The powder feeding rate may be changed by 


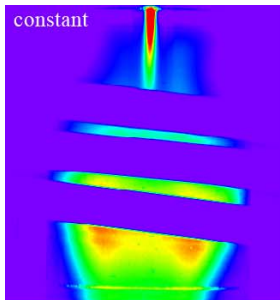

(a)

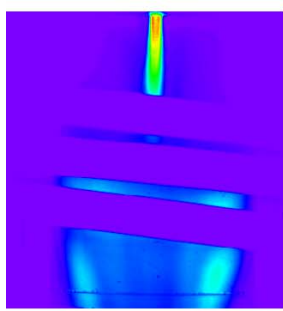

(e)

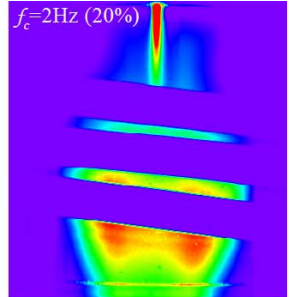

(b)

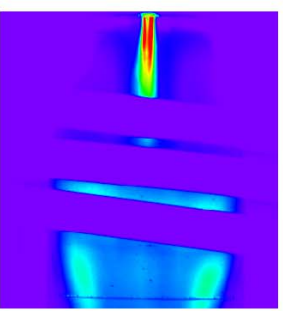

(f)

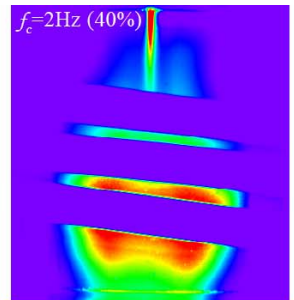

(c)

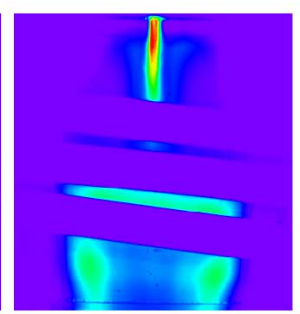

(g)

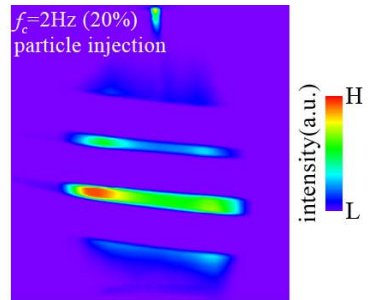

(d)

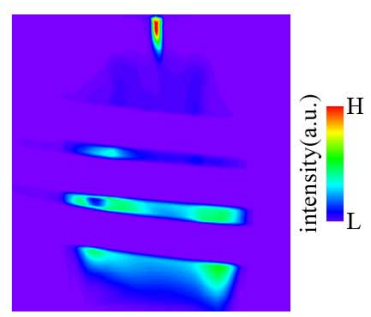

(h)

Fig. 6 Statistically image processed photographs for DC-RF hybrid plasma flow behaviors on (a)-(d) averaged and (e)-(h) standard deviation images, additionally, (a)-(c) and (e)-(g) are without particle injection and $(\mathrm{d})$ and $(\mathrm{h})$ are with particle injection

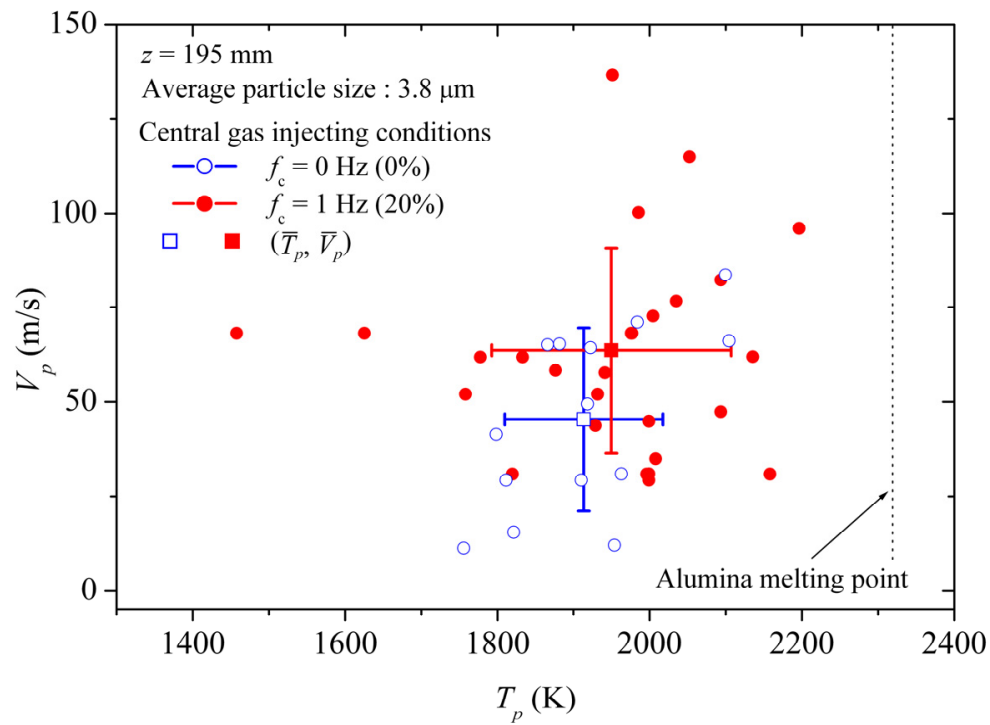

Fig. 7 Correlation between in-flight particle velocity and particle temperature measured at $z=195 \mathrm{~mm}$

the sinusoidal central gas due to suction effect. Because of the pulsation of powder feeding, temporarily high powder loading decreases plasma temperature ${ }^{(12)}$. Therefore, the frequency of the plasma emission seems to increase in the downstream of the RF coil resulting from the drastic decrease in the emission intensity under high particle loading at the high flow rate of central gas.

Figure 6 shows statistically image processed photographs of DC-RF hybrid plasma flow for clear understanding of flow behaviors. The statistical image analysis method helps to understand plasma flow characteristics by estimating the plasma emission intensity and the plasma flow behavior through averaging of 500 sequential raw images ${ }^{(9),(13)}$. The averaged images for $0.5 \mathrm{sec}$ and the standard deviation images are shown in Figs. 6 (a)-(d) and (e)-(h). For the estimation of the Reynolds number, the averaged DC plasma jet velocity of $104 \mathrm{~m} / \mathrm{s}$ at the DC torch nozzle exit was derived from the energy conservation equation considering of the net effective thermal energy of $330 \mathrm{~W}$ by DC plasma jet. The Reynolds 


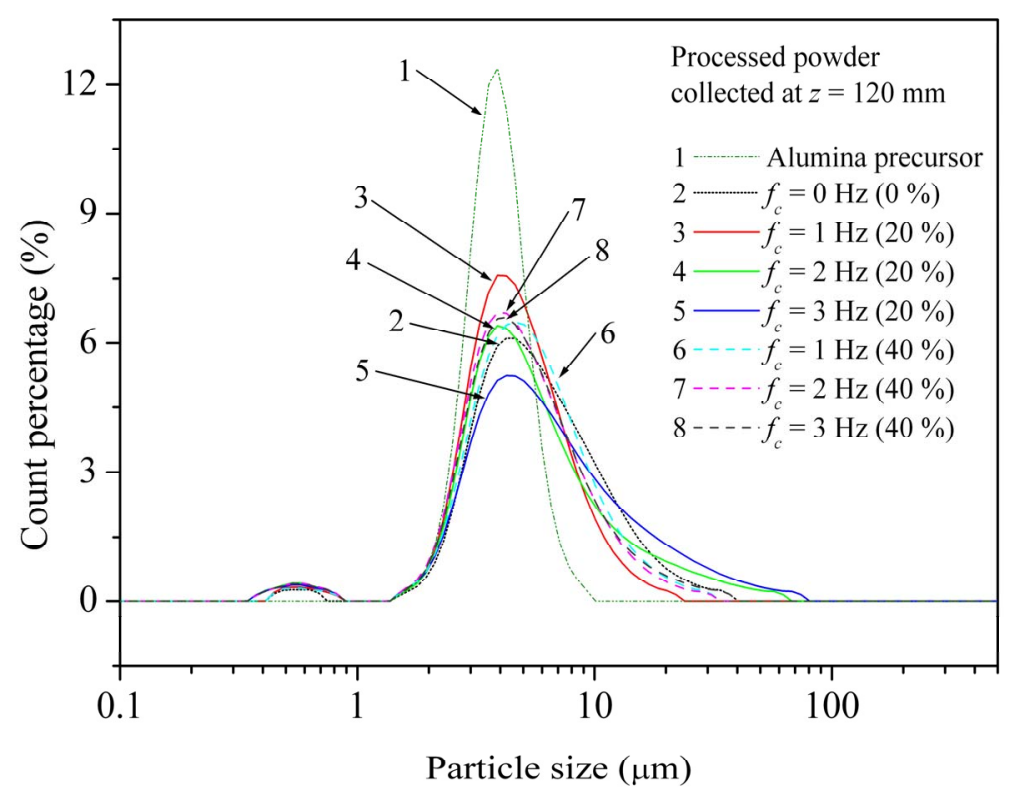

Fig. 8 Effect of sinusoidal central gas injection on size distributions of processed alumina powder

number of DC plasma jet is estimated to be 238 at constant central gas injection as shown in Fig. 6 (a). Then, DC plasma jet is evaluated to be laminar in the constant central gas condition. The averaged and the standard deviation images correspond to the plasma temperature ${ }^{(14)}$ and the quantitative evaluation of plasma fluctuation. Without powder injection, compared with the case of constant central gas injection as shown in Fig. 6 (a), DC plasma jet elongates in average and the high temperature region expands in the lower part of RF plasma flow by sinusoidal central gas injection at $f_{c}=2 \mathrm{~Hz}$ with amplitude of \pm $20 \%$ as shown in Fig. 6 (b); however, the fluctuation of plasma flow is increased especially in DC plasma jet and in the fringe of RF plasma flow as shown in Fig. 6 (f) comparing with Fig. 6 (e). The high temperature region of DC plasma jet becomes shorten for sinusoidal central gas injection at $f_{c}=2 \mathrm{~Hz}$ with amplitude of $\pm 40 \%$, while that of RF plasma flow expands in the RF coil region as shown in Fig. 6 (c) comparing with Fig. 6 (b). The fluctuation of RF plasma flow in the RF coil region increases as shown in Fig. 6 (g) comparing with Fig. 6 (f). Comparing Fig. 6 (d) and (h) with Fig. 6 (b) and (f), the whole emission from plasma flow and the fluctuation in DC plasma jet are reduced by particle injection under sinusoidal central gas, resulting from heat transfer from plasma flow to in-flight particles. Sinusoidal central gas injection obviously expands the high temperature region, while which induces the plasma flow fluctuation.

Figure 7 shows correlation between in-flight particle velocity and particle temperature measured at $z=195 \mathrm{~mm}$ in order to verify the effect of fluctuating plasma flow on in-flight powder behaviors. High temperature region of DC plasma jet periodically elongates by sinusoidal central gas injection as shown in Fig. 4 (a) and (b). Furthermore, particles are transported into the core of RF plasma flow by DC plasma jet momentum. These effects enhance heat transfer between particles and thermal plasma flow, which result in the increase of particle temperature. This is the physical interpretation of the forced active mixing between particles and thermal plasma flow by sinusoidal central gas injection. By giving sinusoidal central gas injection at $f_{c}=1 \mathrm{~Hz}$ with amplitude of $\pm 20 \%$, in spite of increase in the averaged in-flight particle velocity by $40 \%$, the averaged in-flight particle temperature slightly increases by $1.2 \%$ at this measurement point. Therefore, the active mixing between particles and plasma flow occurs at the condition of $1 \mathrm{~Hz}$, compared with the stationary condition. 


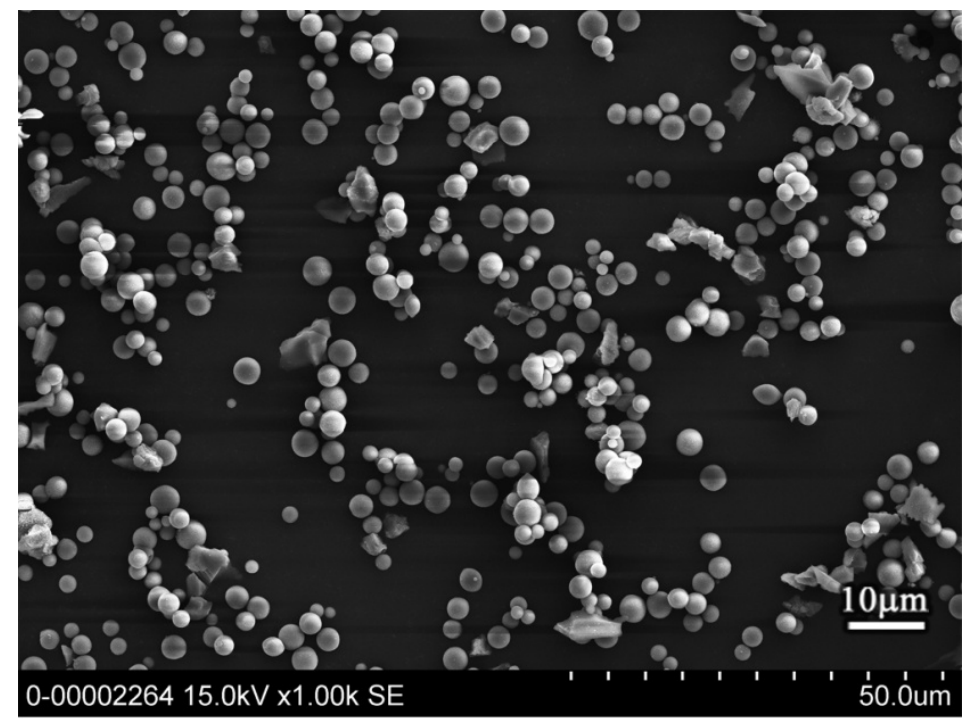

(a)

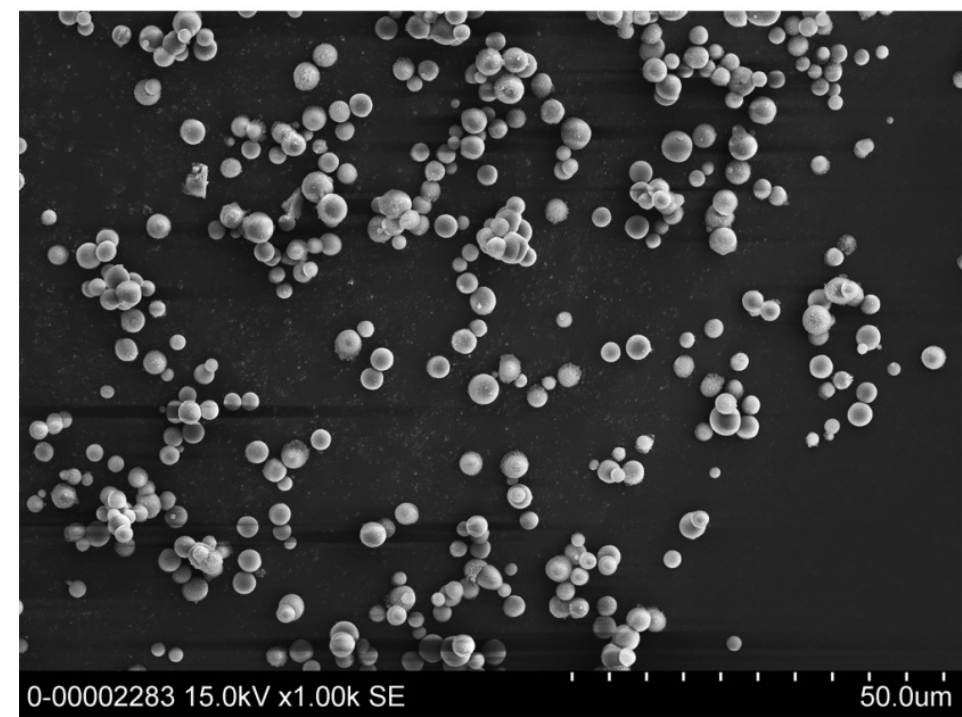

(b)

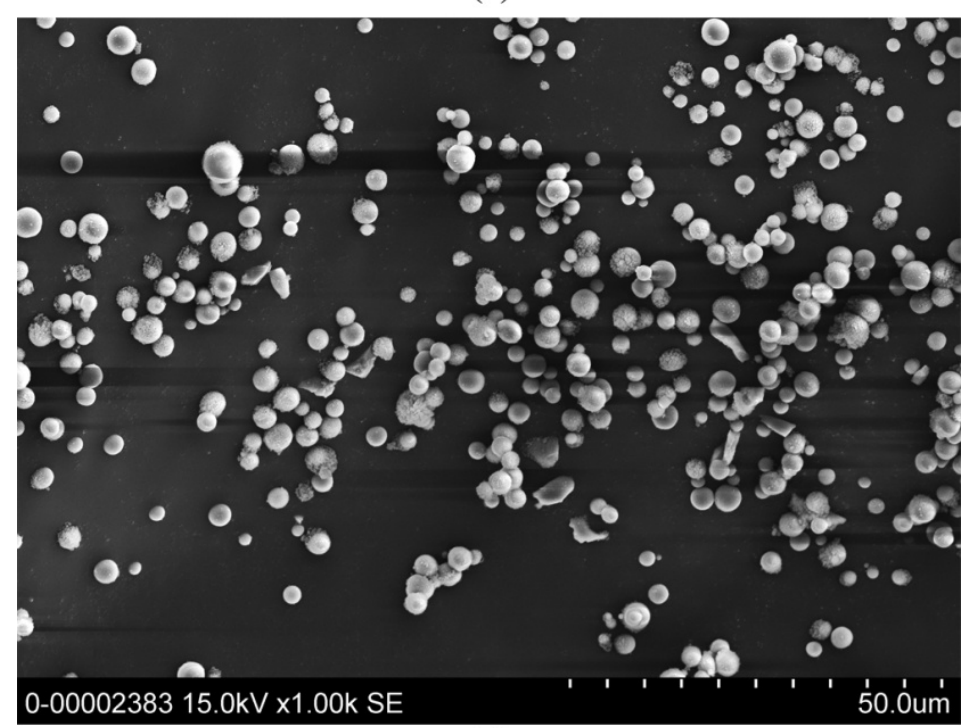

(c)

Fig. 9 SEM morphology micrographs of processed powders for central gas of injecting conditions at (a) constant, (b) $f_{c}=2 \mathrm{~Hz}$ with amplitude of $\pm 20 \%$, and (c) $f_{c}=2 \mathrm{~Hz}$ with amplitude of $\pm 40 \%$ 


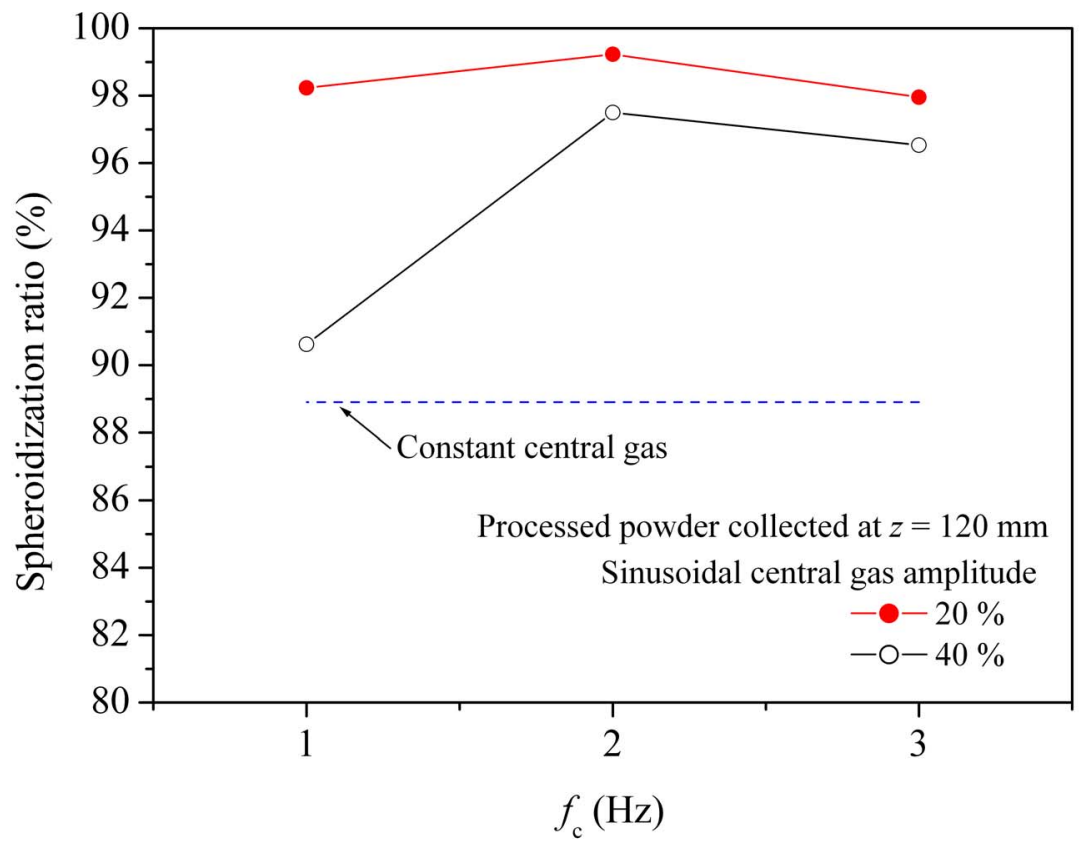

Fig. 10 Effect of sinusoidal central gas injection on spheroidization ratio

Figure 8 shows the effect of sinusoidal central gas injection on size distributions of processed alumina powder. The significant difference of processed powder size is not observed in the size distribution of processed powders collected at $z=120 \mathrm{~mm}$. Because the deposited particles inside the quartz tube at $z=120 \mathrm{~mm}$ during processing are directly and continually exposed to thermal plasma flame, larger particles are produced through particle melting and agglomeration.

Figures 9 (a)-(c) show SEM morphology micrographs of processed powders. These SEM photos clearly show the effect of active mixing by sinusoidal central gas injection on the spheroidization process. The processed particles larger than averaged alumina precursor size shown in Fig. 8 correspond to the partly melted and agglomerated particles by continuous heating on the quartz glass by plasma flow. These agglomerated particles can be found in Fig. 9. As shown in Fig. 9 (a), several untreated particles still remain when injecting constant central gas. On the other hand, after the plasma treatment with sinusoidal central gas injection, processed particles are spheroidized sufficiently as shown in Fig. 9 (b). Comparing Fig. 9 (b) with (c), sinusoidal central gas injection with amplitude of $\pm 20 \%$ is more effective for the spheroidization process than that of $\pm 40 \%$, because of larger area of DC plasma jet emission as shown in Fig. 6 (b).

Figure 10 shows the effect of sinusoidal central gas injection on spheroidization ratio. By giving sinusoidal central gas injection, heat transfer between plasma flow and particles is enhanced by active mixing and spheroidization ratio increases. Sinusoidal central gas with amplitude of $\pm 20 \%$ obtains higher spheroidization ratio for all the frequencies than that with amplitude of $\pm 40 \%$. There is a frequency dependence on spheroidization ratio and the maximum spheroidization of $99 \%$ is obtained at $f_{c}=2 \mathrm{~Hz}$ with amplitude of $\pm 20 \%$.

\section{Conclusions}

The effect of sinusoidal central gas injection on in-flight alumina spheroidization process was experimentally investigated using a DC-RF hybrid plasma flow system at constant low input power. The results obtained from this study are summarized as follows: 
- Sinusoidal central gas injection results in the periodic fluctuation of DC arc voltage due to unsteady axial motion of arc root, as a result, the DC plasma jet length periodically changes with time.

- DC plasma jet elongates and the high temperature region expands in the lower part of RF plasma flow by sinusoidal central gas injection at $f_{c}=2 \mathrm{~Hz}$ with amplitude of \pm $20 \%$. This results in the heat transfer enhancement between plasma flow and in-flight alumina particles by active mixing.

- Effect of sinusoidal central gas injection on spheroidization ratio was made clear. The maximum spheroidization ratio of $99 \%$ for processed powder collected at $z=120 \mathrm{~mm}$ was obtained by giving sinusoidal central gas injection at $f_{c}=2 \mathrm{~Hz}$ with amplitude of $\pm 20 \%$.

\section{Acknowledgements}

The authors would like to thank Mr. Tomoki Nakajima with IFS, Tohoku University, Japan, for his technical support.

The present study was partly supported by the Global COE program Grant, "World Center of Education and Research for Trans. Disciplinary Flow Dynamics" in the Japanese Ministry of Education, Culture, Sports, Science, and Technology.

\section{References}

(1) Jin, H., Xu, L., and Hou, S., Preparation of Spherical Silica Powder by Oxygen-Acetylene Flame Spheroidization Process, Journal of Materials Processing Technology, Vol.210, No.1 (2010), pp. 81-84.

(2) Zeng, Y., Lee, S. W., and Ding, C. X., Plasma Spray Coatings in Different Nanosize Alumina, Materials Letters, Vol.57, (2002), pp. 495-501.

(3) Boulos, M. I., Thermal Plasma Processing, IEEE Transactions on Plasma Science, Vol.19, No.6 (1991), pp. 1078-1089.

(4) Fauchais, P., Boudrin, E., and Coudert, J. F., Plasma Chemistry IV, (1983), pp. 59-186, Springer-Verlag Press.

(5) Yoshida, T., Tani, T., Nishimura, H., and Akashi, K., Characterization of a Hybrid Plasma and its Application to a Chemical Synthesis, Journal of Applied Physics, Vol.54 No.2 (1983), pp. 640-646.

(6) Kawajiri, K., Sato, T., and Nishiyama, H., Experimental Analysis of a DC-RF Hybrid Plasma Flow, Surface and Coatings Technology, Vol.171, No.1-3 (2003), pp. 134-139.

(7) Kawajiri, K., Ramachandran, K., and Nishiyama, H., Statistical Optimization of a DC-RF Hybrid Plasma Flow System for In-Flight Particle Treatment, International Journal of Heat and Mass Transfer, Vol.48, No.1 (2005), pp. 183-190.

(8) Nishiyama, H., Onodera, M., Igawa, J., and Nakajima, T., Characterization of In-Flight Alumina Particle Process Using a Small Power DC-RF Hybrid Plasma Flow System, Journal of Thermal Spray Technology, Vol.18, No.4 (2009), pp. 593-599.

(9) Takana, H., Jang, J., Igawa, J., Nakajima, T., Solonenko, O. P., and Nishiyama, H., Improvement of In-Flight Alumina Spheroidization Process Using a Small Power Argon DC-RF Hybrid Plasma Flow System by Helium Mixture, Journal of Thermal Spray Technology, Vol.20, No.3 (2011), pp. 432-439.

(10) Tiwari, N., Sahasrabudhe, S. N., Joshi, N. K., and Das, A. K., Study of Jet Fluctuations in DC Plasma Torch Using High Speed Camera, Journal of Physics: Conference Series, Vol.208, No.1 (2010), 012134.

(11) Noguès, E., Fauchais, P., Vardelle, M., and Granger, P., Relation Between the Arc-Root Fluctuations, the Cold Boundary Layer Thickness and the Particle Thermal Treatment, 
Journal of Thermal Spray Technology, Vol.16, No.5-6 (2007), pp. 919-926.

(12) Shigeta, M., Watanabe, T., and Nishiyama, H., Numerical Investigation for Nano-Particle Synthesis in an RF Inductively Coupled Plasma, Thin Solid Films, Vol.457, No.1 (2004), pp. 192-200.

(13) Chumak, O., Kavka, T., and Hrabovský, M., Characterization of Plasma Jet Structure and Fluctuations by Statistic Processing of Photographic Images, IEEE Transactions on Plasma Science, Vol.36, No.4 (2008), pp. 1062-1063.

(14) Boulos, M. I., Fauchais, P., and Pfender, E., Thermal Plasmas Volume 1, (1994), p. 327, Plenum Press. 